\title{
A PROPÓSITO DE INSTITUCIONES JUSTAS LA REHABILITACIÓN DE LA RACIONALIDAD MORAL EN RAWLS Y HABERMAS
}

\author{
DELFÍN IGNACIO GRUESO
}

Si se me pidiera por adelantado enunciar los objetivos de este ensayo, diría que el primero es mostrar la forma como el filósofo norteamericano John Rawls y el alemán Jürgen Habermas hacen un uso de una razón construccionista y de una razón dialógica, respectivamente, para darle a la justicia una preeminencia moral que hace tiempo no tenía en la filosofía práctica. Pero ese es un objetivo más interesante para los historiadores de la filosofía que para los juristas, políticos, pensadores sociales y estudiantes de humanidades para quienes escribo este ensayo. A ellos mi segundo objetivo les puede interesar más: mostrar a la justicia como el concepto rector para establecer la moralidad de lo político y de lo jurídico. Para lograr ambos objetivos, poniendo más énfasis en el segundo, seguiré el siguiente orden. Comenzaré (I) mostrando lo que significó reivindicar el concepto moral justicia en el siglo XX, un siglo difícil para la filosofía práctica de vocación normativa. Hecho esto, procederé a (II) mostrar el modo en que ambos pensadores intentan restaurar la moralidad como criterio de legitimidad de las instituciones públicas e intentaré (III) mostrar cómo ese criterio conecta lo constitucional y lo político. En las dos primeras partes comenzaré (1) presentando unas ideas generales, (2) precisaré el caso de Rawls y (3) lo precisaré para Habermas. En la parte III eliminaré las ideas generales, por lo que iré directo a Rawls y luego a Habermas. Este modo de aproximar las filosofías de Rawls y Habermas puede parecer forzado a quienes estén familiarizados con el debate que ellos sostuvieron en 1995. Dejo ese debate para otra ocasión. En este texto, dedicado más a exponer los proyectos que a evaluar los resultados, yo prefiero ahondar en las similitudes, esas que hacían decir a Habermas que su debate con Rawls tenía más bien el carácter intimo de una disputa familiar. 


\title{
1. Las crecientes dificultades para la filosofía política normativa
}

\author{
Por el momento, de todos modos, la filosofía \\ política está muerta. [Laslett, 1956 citado por \\ Rubio Carracedo, 1987:13]
}

1. Podemos suponer que cuando, en 1956, Laslett expedía el acta de defunción de la filosofía política, lo que tenía ante sí era el escepticismo que había venido dominando buena parte del ambiente filosófico hasta inhibir ese tipo de empresa filosófica llamada filosofía política. En cuanto afectaba la capacidad fundante de la razón, este escepticismo llevaba, por un lado, a un realismo político para el cual la política no es más que una cruda práctica del poder, acobardando así la tendencia filosófica a pensar lo político en términos normativos y, por el otro, a un positivismo jurídico para el cual no existe otro derecho que el decidido por una autoridad que logra hacerlo respetar recurriendo si es necesario a la fuerza, acobardando así la tendencia filosófica a preguntarse normativamente por el fundamento de lo jurídico. Así las cosas, en la medida en que este escepticismo triunfaba, lo que moría era esa forma de filosofar que en el Renacimiento engendró utopías que prefiguraban nuevos modos de organización social y política, que en los siglos XVII y XVIII dio a luz los grandes argumentos de corte iuscontractualista que hicieron posible las revoluciones burguesas, y que en el siglo XIX pretendió alcanzar su mayoría de edad con el 'descubrimiento' de las leyes de razón que rigen la moralidad individual, la sociabilidad humana, el Estado y el curso de la historia.

En buena parte de aquel recorrido filosófico, especialmente cuando primó la perspectiva iusnaturalista, la pregunta por lo jurídico y la pregunta por lo político en términos normativos estuvieron estrechamente ligadas a través de una intuición básica: el poder ha de ser legítimo para que pueda erigirse en poder político. Esta intuición es el punto de arranque de la filosofía política y de la filosofía del derecho: la primera enfocando de preferencia la cuestión del fundamento moral del poder político y la segunda el fundamento legal. Para hacer esto, ambas tenían que comenzar con una consideración inicial del poder y del derecho, distinguiendo entre poder de hecho y poder legítimo, así privilegiara una el estudio del poder y la otra el estudio de la norma. En ambos casos, se dice que para que el poder sea válido, debe ser justificado. Esta justificación, dice Fernández Santillán, transformaba una relación de mera fuerza en una relación jurídica, haciendo del consenso el único principio válido de legitimidad del poder político y del poder jurídico, convirtiendo el poder de mandar en un derecho y la obediencia en una obligación. No cabe duda de que esa justificación da origen al fenómeno que en términos de filosofía política llamamos legitimidad y en términos de filosofía del derecho legalidad. Ambos conceptos nos hablan, apelando a diferentes criterios, de un poder válido. El constitucionalismo llega incluso a juntar ambos criterios al señalar como legítimo un poder político que es legal [ver Fernández Santillán, 1985:12-14]. Según Bobbio, Apara el filósofo de la política el problema principal es el de la distinción entre poder de hecho y poder de derecho; para el filósofo del derecho en cambio, el problema principal es el de la distinción entre norma válida y norma eficaz" [Bobbio, 1984:21-22].

He mencionado al iuscontractualismo como uno de los momentos estelares de la filosofía práctica y en el último párrafo he conectado la pregunta por lo legal y la 
pregunta por lo legítimo. Permítaseme que insista en los iuscontractualistas a propósito de la conexión de estas dos preguntas. No lo hago por un prurito de erudicción (pues en este caso el erudito es Bobbio) sino para resaltar, en un texto dedicado a presentar a Rawls y Habermas enfrentados con las tendencias escépticas de nuestra época, cómo esas mismas tendencias estaban presentes, aunque con otros matices, en la época en que filosofaron los iuscontractualistas. Porque, según nos muestra Bobbio, lo que une a los iusnaturalistas no son las premisas de que parten ni la conclusión a que llegan sino su común aproximación metodológica al problema. Según esta lectura, el iuscontractualismo es "una tentativa de dar respuesta segura a las consecuencias corrosivas que los libertinos habían sacado de las crisis del universalismo religioso. No hay autor de la escuela (iusnaturalista) que no tome posición frente al pirronismo moral, aquello que hoy llamaríamos el relativismo ético" [Bobbio, 1979: 18-21]. Y aunque casi todos estos pensadores difieren al considerar los fundamentos del poder político, todos (desde cuando el método se inicia balbuciente con Bodin, Grocio y Althusius, encuentra su madurez con los contractualistas y llega hasta su culminación con Kant) coinciden en Areducir el derecho y lo moral (además de la política) (...) a ciencia demostrativa”. Según Bobbio, este rasgo común entra definitivamente en crisis a partir del ensayo del joven Hegel "De las distintas formas de tratar científicamente el derecho natural" (1802).

A partir de Hegel, incluso a partir de Burke y de los románticos y, después de Hegel, hasta Marx, el siglo XIX ligó la justificación política al espíritu de un pueblo o a cierta lectura de la historia. La futura crisis de estas fundamentaciones filosóficas decimonónicas, apoyadas en alguna idea rectora sobre el destino del hombre o los pueblos o sobre el sentido de la historia, no implicó volver al modo iuscontractualista. El iuscontractualismo parecía haber sido ya suficientemente superado desde las críticas de Hegel y Marx. Tampoco parecía posible volver a convalidar como justificadora una racionalidad que se había revelado más como racionalidad instrumental o que podría ser fácilmente denunciada por sus rasgos etnocéntricos, clasistas, etc. Escéptica frente a la capacidad fundante de la razón, sin atreverse a intentar formular un sentido de la historia o una nueva teoría sobre la naturaleza humana, la filosofía práctica de vocación normativa se mostró incapaz de renovarse a sí misma. Esta incapacidad se proyectó hacia el siglo XX como un ambiente filosófico que tendía a otorgar más prestigio a las corrientes filosóficas que enlazaron razón y poder de tal forma que hicieron imposible mencionar una sin invocar los indeseables tentáculos del otro. Quienes quedaron atrapados dentro de esto, bien pronto llegaron a transformar la tradición crítica del poder en una corriente crítica de la razón.

Esta apatía de la filosofía para fundar lo político y lo jurídico, por otra parte, estaba bien correspondida por un mundo institucional donde la política y el derecho tampoco se creían necesitados de la filosofía. Respaldados en una sociología y una historia política que eran capaces de dar mejor cuenta de la validez de una manera más verificable, y en una ciencia jurídica que no parecía requerir de razones metajurídicas para decir lo que es positivamente válido, lo político y lo jurídico parecían capaces de encontrar por sí mismos su norte.

Pero no puede decirse que la desaparición de las grandes teorías filosóficas de carácter normativo en materia política y jurídica, que tan importantes fueron en la estrategia argumentativa de las teorías liberales, haya significado el fin de todo modo de justificación de esas esferas. Al contrario, una vez que pareció obsoleta la tarea 
filosófica de fundamentar moralmente el orden político mostrando los criterios de obligatoriedad y justicia, la tarea de sostener el orden político acorde con la modernidad burguesa se volvió un problema de gobernabilidad. Ese modo de hablar y de pensar se sostendría por sí mismo como ideología e inspiraría estructuras juridico-políticas estables desde donde se podían promover y proteger los derechos. Los ideales filosóficos habían cumplido su papel [Marx, 1852]. En adelante, la definición de la norma válida y del poder legítimo no tendría que ser defendida en términos estrictamente filosóficos. Una vez organizado el mundo de esa manera, era tarea de las ciencias sociales venir a entender cuándo una norma es válida y un poder legítimo. Es lo que hacen Weber en términos sociológicos y Kelsen en términos jurídicos. Weber parte de una distinción entre poder de hecho y poder de derecho y llega a la tipología de las formas de poder legítimo. Kelsen parte de la distinción entre validez de las normas específicas y eficacia del ordenamiento jurídico en su conjunto y llega al problema del poder jurídico. Y para definir esto no necesitaron hacerlo al modo fundante de la filosofía. Así las cosas, ya en esa época podría decirse que a la filosofía política no le quedaba otra misión que esa que recientemente le ha asignado Richard Rorty: ponerse modestamente al servicio de la democracia [Rorty, 1991: 175-196]. Leslett tenía razón, la filosofía política había muerto.

Esto no quiere decir que durante la primera mitad del siglo XX no se hubieran escrito obras de filosofía política. El marxismo, especialmente el occidental, dio a luz varias de ellas. Es el caso de Gramsci, Rosa Luxemburgo, Horkheimer, etc. Por otra parte, alrededor de la época en que escribe Leslett, autores liberales como Hayeck, Popper, Berlin y otros estaban publicando o habían publicado ciertas obras memorables. Pero esto no podría contradecir el veredicto de muerte porque ninguno de ellos trataba de fundar racional o moralmente, en forma exhaustiva y de manera novedosa, los fundamentos de lo político. Generalmente eran marxistas o liberales atacando las indeseables consecuencias del otro paradigma y tratando de promover las bondades del propio.

Lo que Leslett vio morir, vuelve a renacer con autores como Habermas, quien en su obra Facticidad y Validez presenta un programa moral para "devolver al concepto de razón práctica la fuerza explicativa que ese concepto tuvo antaño en el contexto de la ética y la política", lo cual implica enfrentar con vigor "la intrépida y decidida negación de la razón” en el campo de la filosofía moral de lo político [Habermas, 1992:64-65]. Era una necesidad sentida. Muchos años antes, casi al tiempo en que Rawls publicaba Una teoría de la justicia, otro filósofo alemán, M. Riedel, había publicado una Rehabilitación de la filosofía práctica. Pero no son las obras de Habermas y de Riedel, sino la que acabo de mencionar de Rawls, la que pasa por ser el punto de arranque de esta rehabilitación, según lo reconoce el propio Habermas, para quien esta significó un intento de rehabilitar, "como objeto de investigaciones científicas serias, preguntas abandonadas durante largo tiempo"[Habermas, 1995:41]. Y Habermas no está solo en ese reconocimiento. Un adversario filosófico de Rawls, Robert Nozick, calificó a mediados de la década de los 70 la mencionada obra como Aun trabajo vigoroso, profundo, sutil, sistemático dentro de la filosofía política y la filosofía moral como no se había visto otro igual cuando menos desde los escritos de John Stuart Mill" [Nozick, 1974:183]. El hecho es que, ya para mediados de los 80, esta obra se había Aafianzado como un 'paradigma' de investigación de problemas de filosofía moral y política que ha dado evidentes pruebas de fecundidad (...) (debido) al vigor 
y persuación con que, al hacerse cargo de problemas morales y políticos sustantivos, se ha enfrentado al escepticismo que durante décadas ha permeado la cultura académica acerca de la posibilidad de abordar racionalmente cuestiones prácticas" [Rodilla, 1986:IX-X].

Ahora bien, la forma como Rawls y Habermas enfrentan a las tendencias escépticas hacia la filosofía normativa es distinta y, sobre todo, son distintas las formas como esas tendencias se expresan en el mundo filosófico del cual emerge cada pensador. Por lo tanto, para matizar un poco este apresurado balance de la filosofía práctica hasta mediados del siglo XX, conviene revisar más de cerca el ambiente filosófico que enfrenta cada uno de estos pensadores.

2. Para el tiempo en que Rawls publica sus primeros ensayos, existía en Norteamérica una larga hegemonía de ciertas posturas metaéticas y una gran influencia de la filosofía analítica y su vocación cientificista. La reflexión sobre asuntos sustantivos de la ética había cedido el paso a una tarea que parecía más seria, el análisis de las propiedades formales del lenguaje moral. Tal desplazamiento hacia lo analítico equivalía a un descreimiento de las posibilidades de la filosofía práctica. Principia Ethica, publicada por G. E. Moore en 1903, que presenta las teorías morales como ocupadas en 'falacias naturalistas', pasa por ser un punto de arranque claro de este descreimiento [ver Rodilla 1986 y Syre-McCord 1988]. La tesis de Moore, según la cual 'bueno' y 'malo' son conceptos inanalizables, es igualmente sostenida por A. J. Ayer, quien en 1952 escribió que A la filosofía ética consiste simplemente en decir que los conceptos éticos son pseudoconceptos y por lo tanto inanalizables", lo que niega la posibilidad de una ciencia ética, Asi por ciencia ética entendemos la elaboración de un 'verdadero' sistema de moralidad ". Ayer termina por recomendar que la ética, como rama del conocimiento, sea "un departamento de la psicología y la sociología” y aclara que la casuística de los sistemas morales, que no es una ciencia sino una investigación analítica, no debe ser considerada más que "un puro ejercicio de la lógica formal" [Ayer, 1952: 34].

Cuando Rawls orienta su proyecto a superar "la teoría sistemática predominante en la filosofía moderna (...) el utilitarismo" [Rawls, 1971:9], un utilitarismo que él ve comenzando con Hume y Adam Smith, pasando por Mill y terminando con Edgeworth y Sidgwick, no sólo tiene que enfrentar el desestímulo que las reflexiones de Moore, Ayer y otros impusieron sobre el campo filosófico de la ética y la política y que casi prohibía inmiscuirse en prescripciones que pusieran en peligro la deseada seriedad del discurso filosófico; también tenía que enfrentar el decisionismo amoral que, a los ojos de nuevas teorías democráticas, regía el mundo político. En efecto, la democracia, ese criterio normativo sobre la legitimidad del poder político que se había venido imponiendo desde comienzos del siglo XX, había sido analizada por Joseph Schumpeter en 1942 en términos de sociología política y había quedado reducida a una forma de estabilidad dependiente más de la manipulación que del consenso moral. Las teorías clásicas de la democracia, sostuvo Schumpeter, son inadecuadas no sólo como descripciones sobre el funcionamiento real de los gobiernos democráticos, sino también como justificación de las instituciones y prácticas democráticas. En lugar de la definición clásica de la representación, que más o menos supone un pueblo con una opinión definida y racional sobre cada asunto y capaz de elegir los representantes que llevarán esa idea a la práctica, Schumpeter propuso 
definir la democracia como " esa estructura institucional para la toma de decisiones políticas en la cual los individuos adquieren el poder de decidir a través de una lucha competitiva por el voto de la gente" [Schumpeter, 1942:95]. La democracia aparecía ahora como un simple modus procedendi ante el cual lo normativo se mostraba fatuo y para el cual no hacía falta una moralidad política intersubjetiva.

Si la democracia podía funcionar así, era también gracias a que las grandes ideas utilitaristas habían hecho su trabajo -en la medida sesgada e indirecta en que los pensamientos filosóficos lo pueden hacer- sobre la opinión pública predominante, una opinión pública más afín con un realismo político capaz de aceptar el quehacer político como un simple decisionismo tecnocrático con sanción electoral. Si, pese a la complejidad de las doctrinas utilitaristas, algo logró quedar como verdad utilitarista en la opinión pública, fue esto: "como no hay verdades definitivas y como nadie tiene un voto que valga más que el de los demás, lo que diga la mayoría será tomado como lo definitivo hasta nueva orden”. Esto no obsta para que, en términos del discurso consciente, los ideales patrióticos, los valores democráticos y todas esas ideas sobre las cuales se elaboran los discursos políticos, fueran también un componente de la motivación electoral. Pero los discursos no serían otra cosa que malabarismos lícitos dentro de un amoral decisionismo.

Ahora bien, aunque un estado de cosas así podría ser muy eficaz por un tiempo, en el largo plazo termina liquidando el fundamento moral del orden político y podría comprometer esa misma eficacia. Al no haber vínculos intersubjetivos, una simple sumatoria de individualidades moralmente desvinculadas no garantiza un orden político legítimo y nada garantiza hacia el futuro la estabilidad del régimen. No parece posible esperar una duradera estabilidad política sobre bases puramente cínicas o racional-instrumentales, porque la misma apelación usada para la legitimidad del régimen bien puede usarse para su negación. La desnudez moral del realismo político es autofágica.

3. De manera similar, cuando Habermas emprende su rehabilitación de la filosofía práctica se enfrenta a un mundo filosófico hostil. En su caso, la hostilidad a la filosofía práctica le viene casi de lo que pudiéramos llamar su nicho original, la vieja Escuela de Frankfort. Tiene que comenzar por enfrentar una tradición de crítica a la 'racionalidad instrumental' y sus nefastos efectos sobre lo político y lo social. Sus maestros Horkheimer y Adorno habían concluido que los ideales de la Ilustración habían llegado finalmente a un estado de control social sobre los asuntos públicos, un control que estaba lejos de ser una sana opinión pública fundadora de lo político. Ellos habían hecho notar que, aunque la Ilustración había soñado con "liberar a los hombres del temor e imponer su soberanía", hoy "toda la tierra ilustrada irradia un desastre

triunfante”[Horkheimer y Adorno, 1944:196]. Tal desastre no podría explicarse sino por un develamiento del carácter ideológico de la Ilustración, con el cual ella termina legitimando nuevas formas de dominación. En resumidas cuentas, la Ilustración consistía "sobre todo en el cálculo de la eficacia y de las técnicas de producción y distribución; de acuerdo con su contenido, la ideología compagina con la idealización de la existencia y del poder que controla la tecnología” [Horkheimer y Adorno, 1944: xvi]. Casi coincidiendo con las ideas de Marx acerca del trabajo alienado y su relación con la naturaleza, Adorno y Horkheimer habían concluido, que en la medida en que instrumentalizaban las cosas, los hombres 
ilustrados se comportaban como dictadores y trataban de instrumentalizarse los unos a los otros.

A similares conclusiones habrían de llegar otros pensadores del siglo XX que analizaron los efectos de la modernidad política y con los cuales Habermas se enfrenta en su Discurso Filosófico de la Modernidad (Luhmann, Derrida, Foucault y otros). Según ellos, en lugar de expresar una moralidad, la razón se mostraba como una mera racionalidad instrumental al servicio de una voluntad de dominio, en la forma vista por Nietzshe; de las pulsiones, en la forma vista por Freud o de las necesidades del mundo socioeconómico, en la forma vista por Marx. A falta de una razón trascendental, se tenía la amarga vivencia de una racionalización del orden social, estudiada en términos sociológicos por Weber como la característica determinante de la modernidad, que en vez de llevar a los seres humanos a un orden social y político justo, los había llevado al campo de concentración de Auschwitz.

Demostrar que esto no es necesariamente así ha sido un esfuerzo constante en la obra de Habermas. Y tal demostración pasa por una revalidación de la razón moral de cara a lo político. Por supuesto, Habermas no niega la razón que le asiste a quienes critican el curso que siguió la razón práctica una vez consolidado el mundo capitalista. Buena parte del problema es que la razón práctica que debía iluminar la realidad política ha quedado atrapada en la subjetivación típica de la modernidad. Por eso propone que Ael lugar de la razón práctica sea ocupado por la razón comunicativa". La ventaja de la razón comunicativa, según Habermas, es que, a diferencia de la vieja razón práctica, Ano queda atribuida al actor particular o a un macrosujeto estatal-social (sino) al medio lingüístico" [Habermas, 1992:65]. Ya en Acción Comunicativa y Conciencia Moral había dicho que la acción comunicativa le abre camino a la razón moral por cuanto permite salirle al paso al escepticismo moral', pues en ella los juicios morales realmente si tienen contenido cognitivo; al 'relativismo moral' ya que cualquiera que tome parte en una argumentación es en principio capaz de alcanzar los mismos juicios; y al "materialismo moral', pues se elimina lo no generalizable de las éticas particulares y se puede apuntar con exclusividad a la justicia [Habermas, 1983:120-121].

Concluyo esta parte con unas palabras de transición hacia la siguiente. Comenzaré por reconocer que a Habermas le cabe el mérito de haber emprendido ese proyecto al tiempo que se ocupaba de criticar la tradición escéptica sobre las posibilidades fundadoras de la razón, mientras que Rawls, que no se interesa mucho en criticar otras tendencias filosóficas, tiene el mérito de haber sido el pionero. Es indudable que él generó sus detractores-correctores, quienes sólo han venido a trabajar dentro del territorio abierto por la agenda rawlsiana. Porque, bueno es no olvidarlo, fue en torno a ella donde primero se identificaron libertaristas, comunitaristas, neoutilitaristas y construccionistas, y es ella la que da sentido a ideas como las de Dworkin, Nozick, Ackerman, Walzer, Kymlicka, van Parijs, Taylor y otros.

Ahora bien, tanto Rawls como Habermas tienen que evitar que sus propias restauraciones de una racionalidad moral fundadora del orden político afronten las dificultades que dieron al traste con proyectos anteriores. La osadía de Rawls radica en que, conociendo las dificultades, emprende un modo de fundación del orden político que es claramente contractualista. Llevándolo a un refinamiento tal, llamado ahora constructivismo politico, se permite encargarle a ese modo la tarea de determinar lo que es una sociedad justa. No menor es el mérito de Habermas quien, de una 
manera menos evidente, también apela a lo que en Kant podría pasar por un modo contractual de legitimar el orden político. Esta es la idea de unas reglas que los ciudadanos se den a sí mismos (o, para decirlo de otro modo, 'se den unos a otros') como si fueran personas morales libres e iguales. En ambos casos, la rehabilitación de la condición de que, para que un ordenamiento político de la sociedad fuera aceptado como legítimo, éste tenía que ser justo, implica trasladar el criterio de legitimidad del consenso fáctico de los gobernados (donde tan acertadamente lo colocó Max Weber para efectos explicativos) a una categoría prescriptiva de estirpe claramente moral: la justicia. Veamos cómo se justifica esa prescripción.

\title{
2. Redefiniendo lo justo al modo Kantiano
}

\begin{abstract}
Mientras Rawls da por sentado 'el punto de vista moral', usándolo para derivar principios substantivos de un orden social y politico justo, Habermas apunta a fundamentar el punto de vista moral mismo [Moon,1995:145]
\end{abstract}

1. En Rawls, el tema de la fundamentación moral del orden institucional a partir de un concepto de justicia está presente casi desde el comienzo de su obra. No creo, en cambio, que ese haya sido el tema central del programa filosófico de Habermas. Esa centralidad es más bien un fenómeno tardío en el desarrollo de su obra y viene en gran parte, mucho más de lo que los habermasianos están dispuestos a conceder, de la influencia del propio Rawls. Si los desarrollos investigativos que le permitieron llegar a su teoría de la acción comunicativa son los que van desde Frege y Pierce hasta Piaget y Koelberg, entre otros, los de Rawls vendrán después a ayudarle a pensar las consecuencias morales de dicha teoría. Más concretamente, aparecen a partir de 1983 y primero como un objeto de crítica; sólo después se nota claramente que es un modelo y que, de ser objeto de una crítica más o menos externa, Rawls se irá volviendo para Habermas un interlocutor dentro de una "disputa familiar" [Habermas, 1995:42]. En verdad, el modo de filosofía moral que Habermas emprende, en cuanto es crecientemente kantiano, lo es en el sentido rawlsiano. Eso se puede observar en lo que Habermas llama 'el punto de vista moral'.

En fin, hoy por hoy ambos coinciden en ese propósito y ligan su indagación al problema de las instituciones en un régimen democrático habitado por individuos que se consideran a sí mismos libres e iguales. Esa coincidencia (reconocida por Habermas, no aún por Rawls) vincula ambos con lo más excelso de la tradición filosófica práctica moderna. Y los pone también en frente de las dificultades contemporáneas para la elaboración filosófica prescriptiva, al tratar de definir lo justo, y hacer de la justicia un valor vinculante y eficiente, cuando hay tantas culturas, religiones, filosofias e ideologías que pueden tener su propia noción de lo justo y lo bueno.

La pista la da el modo kantiano de entender lo justo. Para desarrollar ese modo en una versión nueva y hacerla capaz de eludir el problema que presenta la diversidad de doctrinas y cosmovisiones del mundo contemporáneo, nuestros dos autores tienen que corregir lo que perciben como deficiencias en el propio modo en que procedió Kant. Para Rawls, esas deficiencias se expresan en las connotaciones metafísicas que 
hacen de la kantiana una aproximación a la justicia más bien incapaz de ganar la aceptación de las diversas doctrinas y cosmovisiones que habitan las sociedades democráticas contemporáneas. Para Habermas, en la casi indiferencia para con la realidad social que parece tener la moralidad kantiana, haciendo que ella descuide el cálculo de las consecuencias de las acciones y que se defina con una independencia casi absoluta de las cuestiones de vida buena, que tan importantes han sido en la filosofía moral clásica y que Kant pone casi al nivel de las decisiones irracionales. Veamos un poco las ideas generales de Kant sobre la justicia y el derecho y luego, la reformulación hecha por cada uno de los dos pensadores.

Cuando Kant piensa el derecho, lo piensa más próximo a la moralidad de la justicia que a las nociones empíricas sobre lo que es bueno. En general, para Kant, el concepto de derecho sólo tiene sentido bajo las siguientes condiciones: "Primero, es válido únicamente para las relaciones externas y prácticas de una persona con otra (...). Segundo, es válido únicamente para las relaciones de una voluntad con la voluntad de otro, no con sus deseos o intenciones (...) Tercero, no toma en consideración el contenido de la voluntad, es decir, el fin que la persona intenta realizar(...). El derecho es por lo tanto un agregado de esas condiciones bajo las cuales la voluntad de una persona puede ser puesta en relación con la voluntad de otra de acuerdo con una ley universal de libertad (...) El derecho estricto sólo puede ser representado como la posibilidad de un uso recíproco general de la coerción que es consistente con la libertad de cada uno de acuerdo con leyes universales" [Kant, 1797: 38-39].

Esta idea de uso recíproco de la coerción consistente con la libertad de cada uno es materializada en la posición original de Rawls y, de un modo un poco distinto, en el principio de universalización de Habermas. En ambos casos, en términos generales, las partes involucradas en una disputa tienen que decidir los principios de justicia haciendo un uso moral de su racionalidad. Hasta cierto punto, lo que define ese uso moral es la ley de la libertad al modo kantiano: "Una acción es conforme a derecho cuando permite, o cuya máxima permite, a la libertad del arbitrio de cada uno coexistir con la libertad de todos según una ley universal" [Kant, 1797:39]. En otras palabras, la libertad de cada agente debe ser consistente con la libertad de cada otro agente. De allí recibe la ley su objetividad, es decir, que aparezca como moralmente objetiva.

Como se ve, la objetividad moral no depende de alguna doctrina de la virtud. Es allí donde cobra relevancia la diferenciación que Kant hace entre deberes de virtud y deberes de justicia, fundamental para distingir entre éticas de la virtud y éticas del deber (llamadas por Habermas moralidad en sentido pleno). En general, un deber es un constreñimiento de la voluntad. Kant lo definió de modo similar en diferentes textos: el deber es "la limitación de la voluntad a lo que requiere una legislación universal que se hace posible a través de la adopción de una máxima” [Kant, 1793:72]. El deber es "la acción a la cual una persona está atada" [Kant, 1797:279]. Y hay, al menos, tres parejas contrastables de deberes: 1. Deberes para con nosotros mismos y deberes para con otros. 2. Deberes perfectos e imperfectos. 3. Deberes de virtud y deberes de justicia. Los deberes de virtud son llamados por Kant deberes reales, porque ellos expresan en sentido estricto lo que es un deber, al menos para un hombre libre, pues en cuanto "es un ser libre (moral), la noción de deber sólo puede ser autoconstreñimiento (...)” [Kant, 1797:290]. Los deberes de virtud no son más que deberes autolegislativos y como la justicia sólo tiene que ver con las relaciones externas entre individuos, esos deberes quedan excluidos. En conclusión, la distinción entre los 
deberes de virtud y los deberes de la justicia es "que sólo los últimos son externamente compelibles, mientras que los primeros descansan en el autoconstreñimiento"[Kant, 1797:293]. Sólo los deberes de justicia son controlables en términos jurídicos y políticos. Esto no disminuye sino que afirma el carácter deontológico de la moral del deber, pues "el sistema de la deontología general se divide en jurisprudencia, capaz de establecer leyes externas, y ética, que no es capaz de ello" [Kant, 1797:289]. La jurisprudencia tiene que ver con la condición formal de la libertad exterior, es decir, con el derecho. Kant lo dice de modo preciso: "Podemos concebir la relación de un fin con un deber en dos modos: comenzando con el fin hasta encontrar la máxima de las acciones ajustadas a deber, o, al contario, salirnos del fin para encontrar el fin que sea también un deber. La jurisprudencia procede del modo primero. Se deja a la libertad de cada cual elegir libremente el fin a escoger para sus acciones" [Kant, 1797:292].

Pero esto no quiere decir que la jurisprudencia sea sólo un marco externo y que la libertad y la moralidad sólo se pueda conseguir huyendo al reino interior, donde de verdad reine el deber o donde podamos escoger un deber. Al contrario, la moralidad debe estar ya presente en el orden externo de la jurisprudencia para que pueda ser compatible con la ética interna, para que los hombres se sientan bajo el imperio de una sola legislación y, por cierto, de una legislación moral. Kant expresaba esto como una necesidad de que la legalidad aparezca como una necesidad objetiva, es decir, que las leyes "son válidas en la medida en que tienen una base a priori y pueden ser vistas como necesarias". Cuando esto ocurre, la legislación es capaz de prescribir acciones externas e internas, uniendo así una ley (que objetivamente presenta la acción que debe ser hecha, que hace de ella un deber) y un motivo (que conecta subjetivamente con la idea de la ley la razón de la voluntad electiva para esta acción). Cuando el motivo es el deber, la legislación es ética. Cuando el deber no es el motivo, la legislación es jurídica. La moralidad aparece cuando la idea de deber que brota de la ley es también el motivo de la acción. [Kant, 1797:270],

Todo esto está bien con respecto a Kant. Pero ) ¿cómo ayuda esto a resolver el problema de las sociedades democráticas modernas, habitadas por distintas doctrinas, ideologías y culturas, cada una con sus propias nociones de lo bueno y acaso también de lo justo? )Puede esto ayudar a encontrar una noción de justicia que guíe el diseño de las instituciones y la producción y renovación del derecho? Al parecer, ayuda. Por lo menos a nuestros dos pensadores les ha servido para establecer, a partir de la distinción kantiana entre 'asuntos de vida buena'y 'asuntos de justicia', una distinción rawlsiana entre entre good (bueno) y right (correcto) y habermasiana entre 'moralidad' y 'eticidad' En ambos casos les sirve para llegar a una moralidad política postconvencional, una moralidad política pensada con independencia de los 'asuntos de vida buena'que Habermas, siguiendo la terminología hegeliana, llama 'eticidad', 'valoraciones éticas de lo bueno' o simplemente 'éticas convencionales', y que Rawls llama doctrinas comprehensivas de lo bueno. Rawls dio el primer paso al establecer que su justicia como equidad pertenece a una moralidad relacionada con lo justo y que se aplica sólo al campo de lo público. Esa moralidad, pretende liberarse en gran medida además, de las connotaciones relativistas de las éticas de los pueblos, las ideologías y las épocas. Recientemente ha independizado su moralidad política de lo que él considera ha sido la filosofía moral tradicional y la ha llevado a ser una moral estrictamente política. Habermas ha obrado de modo similar al independizar de tal modo su propuesta de acceder a 
un punto de vista moral de ciertos nexos indeseables con las posiciones éticas, que ha tenido que precisar que su ética del discurso debería llamarse en rigor moralidad del discurso.

En la medida en que ambos pensadores intentan alcanzar esa moralidad, ambos vuelven a acercarse a Kant: Rawls a través de un complejo sistema de argumentación y decisión de lo que es justo, articulado en torno al dispositivo conocido como la posición original, y Habermas a través de una situación ideal de habla, fundamental para el logro de la justicia, un poco distinta a la de Rawls. No en vano coinciden en algo: Rawls ha dicho que su posición original puede entenderse como una interpretación procedimental del imperativo categórico kantiano y Habermas ha dicho que su pricipio de universalización puede entenderse como una interpretacion intersubjetiva del mismo imperativo. Veamos esto un poco.

2. Casi desde el comienzo, Rawls conecta su concepción de la justicia con la noción de equidad y termina por llevar esa noción hacia una moralidad capaz de reorientar la organización social, la relación de lo privado con lo público y la vocación de lo institucional. En lo que toca a la legislación, ella también debe corresponder a una noción de equidad entre ciudadanos libres e iguales. No debiéndose a las éticas de la virtud, la única condición que una legislación debe siempre tener a la vista es ésta: la libertad de cada agente debe ser consistente con la libertad de cada otro agente de acuerdo con una ley universal. Rawls eleva esto a la categoría de un primer principio de justicia. A partir de esta condición se pueden definir los derechos, que en buena parte no aparecen en Rawls como derechos naturales sino como bienes primarios, es decir, como medios para el logro de los fines que los agentes sociales persiguen de acuerdo con su propia concepción de lo bueno. En otras palabras, lo justo se define con independencia de lo bueno e incluso de los derechos. Luego, los derechos deben servir para perseguir lo bueno siempre y cuando no destruyan ese primer principio de la justicia ya enunciado. A fin de que el primer principio no se quede en un formalismo jurídico, indiferente ante la real distribución de oportunidades, la justicia rawlsiana obliga a atender a las condiciones de desigualdad que en las sociedades impiden la realización de la libertad y el logro de los fines que los individuos se proponen de acuerdo con su concepción de lo bueno, incluso si esa concepción es conciliable con el primer principio. Se postula entonces el segundo principio de justicia, no como una forma de buscar una igualdad final, sino una igualdad de la libertad inicial. En un momento volveré sobre estos principios. Lo que me interesa señalar por el momento es que no hay en Rawls una preocupación inicial por los derechos; ellos aparecen como subsidiarios de la justicia. Es la sociedad como un todo lo que interesa y Rawls toma la justicia como la primera virtud de la sociedad [Rawls, 1971:3].

Si se trataba de pensar una sociedad virtuosa, habría que pensarla como aquella donde hay una moralidad que guía la producción del derecho, eso que Kant llamaba una máxima de objetividad. Rawls tiene que establecer las condiciones que hagan de la teoría de la justicia una teoría moral, a fin de que ella pueda regir la producción del derecho en las sociedades democráticas. Esta es la función asignada a las condiciones racionalistas que dan forma a la posición original y al velo de ignorancia. $\mathrm{Su}$ función es proveer objetividad a los principios de justicia.

3. En el caso de Habermas, lo post-convencional es garantizado de un modo un poco 
más complejo, nutriéndose de los contextos culturales, religiosos, étnicos y sociales donde los individuos logran su identidad y, a la vez, separándose de esos mismos contextos. De esa forma, Habermas intenta entroncarse más directamente con las tradiciones aristotélica y hegeliana de la moralidad política, al tiempo que evita la disolución de dicha moralidad en lo que son las vidas éticas concretas incorporadas en las religiones, culturas, etnias, etc. Sólo así podría garantizar una moralidad válida en medio de la diversidad. Permítaseme que presente todo esto a través de lo que hay de hegeliano y de kantiano en el modo habbermasiano de definir la moralidad de las instituciones. Comienzo con una reflexión sobre la racionalidad práctica que pretende ubicar claramente a qué tipo de racionalidad práctica pertenece la moralidad política. Según Habermas, las relaciones entre la razón práctica y algunos puntos de vista morales de la tradicion filosófica occidental se deciden por la pregunta ¿qué debo hacer?, pregunta que siempre se refiere a un asunto de justificación entre cursos de acción alternativos. Hay tres tipos de variación de esa pregunta. Preguntas pragmáticas, referidas a asuntos de la racionalidad intencional, aquellos que se resuelven a través de imperativos técnicos y pragmáticos, es decir aquellos relacionados con causas y efectos de acuerdo con preferencias de valor. Preguntas éticas, referidas a asuntos de buena vida, es decir aquellos en los que el ejercicio de la razón práctica es dirigida al bien y no meramente a lo posible. Ellos se refieren a lo que Taylor llama "preferencias fuertes', aquellas que tienen que ver no sólo con las disposiciones contingentes y las inclinaciones, sino con el auto-entendimiento de una persona, su carácter y modo de vida y su identidad individual. Preguntas morales, referidas al modo en que mis acciones afectan los intereses de los demás y llevan a conflictos que deberían ser regulados de una manera imparcial, "es decir, desde un punto de vista moral" (Habermas, 1993:5). Ahora bien, si conectamos esos tipos de pregunta con los tres modos filosóficos tradicionales de ver la relación entre la razón práctica y la moralidad, identificamos tres modos: el kantiano, el empirista y el neoaristotélico. Para Kant, la moralidad es coextensiva con la razón a través de una plena autonomía en la que razón y voluntad son equivalentes. Para el empirismo, la razón práctica es asimilable a su uso pragmático, al ejercicio intencionado del entendimiento. Para la tradición aristotélica, especialmente en su versión comunitarista, la razón práctica es asumida con el rol de una facultad de juicio que ilumina el horizonte histórico de un ethos hecho de costumbres. Habermas intenta hallar su propio modo a través de una ulterior clasificación desde la relación de la razón práctica con lo pragmático, lo ético y lo moral. Aquí es donde cobra sentido la elucidación de lo hegeliano y lo kantiano de que ya hablé antes.

Lo que podría llamarse hegeliano en Habermas es su capacidad para acercarse un poco a las posiciones comunitaristas (neoaristotélicas) que eluden las construcciones racionales formales, universalizantes y ahistóricas. A través de este rasgo hegeliano, Habermas recupera, en contra de los esfuerzos de la razón filosófica monológica y descontextualizada, la riqueza de las vidas éticas concretas, las tradiciones y consensos éticos de los contextos culturales específicos, todo lo que los pueblos han ido decantando como sistemas de valores. Así que, si de reconstruir el imperativo categórico se trata, los contextos valorativos específicos deben proveer la orientación principal. Esto además permitirá lograr para la justicia una solidaridad que no aparece claramente en la moralidad kantiana. Por eso, la ética del discurso no "excluye de la esfera de la problematización las cuestiones relativas a la vida buena a las cuales las 
éticas clásicas le dieron preeminencia, abandonándolas a las disposiciones o decisiones irracionales" [Habermas, 1991: 1-2]. La resultante sería una moralidad política cuya fuerza motivacional es otorgada por los contextos específicos en virtud de sus eticidades. Es por eso que, "como Hegel, (la ética del discurso) insiste, aunque en el espíritu de Kant, en una relación interna entre justicia y solidaridad. Intenta mostrar que el significado del principio básico de moralidad puede ser explicado en términos del contenido de las proposiciones inevitables de una práctica argumentativa que puede ser intentada sólo en común con otros. El punto de vista moral desde el cual podemos juzgar las cuestiones prácticas de una manera imparcial está ciertamente abierto a diferentes interpretaciones" [Habermas,1991:1].

Pero Habermas no es un comunitarista, es decir, no considera que las diferentes eticidades puedan proveernos por sí solas las soluciones a nuestros conflictos valorativos. Al contrario, lo ético nos lleva más bien a reafirmar nuestras valoraciones en contra de las 'transgresiones y diferencias'. Cuando nos apoyamos en nuestro entorno ético, difícilmente podemos adoptar 'el ojo de Dios', esa mirada serena y superior que la neutralidad de la justicia exige. Para poder atender a los conflictos valorativos, debemos evitar lo que Habermas considera una indeseable consecuencia del comunitarismo: la disolución de la moralidad en la vida ética [Habermas, 1993:1]. Y eso sólo se puede lograr desde el punto de vista moral kantiano.

Al igual que Kant y que Rawls, Habermas vincula lo moral a la preocupación por la justicia y entiende la justicia como un punto de vista capaz de resolver conflictos entre intereses y valores. Habermas dice que "la ética del discurso se ubica dentro de la tradición kantiana pero sin exponerse a las objeciones a que se exponen las éticas abstractas de la convicción por causa de su concepción" [Habermas, 1993:1]. Como Kant, Habermas hace depender el punto de vista moral de una voluntad autónoma aunque, en este caso, una voluntad autónoma 'mundana', por así decirlo, no tan pura como la kantiana pero más realista y capaz de nutrirse de las fuerzas motivacionales que sólo pueden proveer los contextos específicos de solidaridad. La argumentación ayuda a construir esa buena voluntad a través de la fuerza de las buenas razones.

A fin de poder asumir un punto de vista imparcial, la ética del discurso "adopta una concepción muy específica de moralidad que se circunscribe a las cuestiones de justicia” [Habermas, 1993:2] y de esa forma se eleva, por así decirlo, sobre los sistemas éticos. Es por esto que, en sentido estricto, la ética del discurso debería ser llamada moralidad del discurso, en cuanto que es una ética post-convencional que difiere de los sistemas éticos que nutren a los individuos en virtud de su pertenencia a ciertos contextos sociales, culturales, religiosos, etc. La ética del discurso, se ocupa de los problemas de la justicia, incluso de la justicia entre esos mismos sistemas éticos.

En cuanto concentrada en la justicia, la ética del discurso ofrece una explicación del punto de vista moral justo, explicación que tiene que darse en términos de presuposiciones comunicativas de argumentación. Este logro se concreta en el principio de universalización o Principio $U$, que señala que una norma es válida si satisface la condición de ser aceptada por todos los afectados por ella, previa evaluación de todas las consecuencias y efectos colaterales de su observación general. De esa forma, "no adherimos a reconocer normas por un sentido de deber porque ellas hayan sido impuestas sobre nosotros mediante la amenaza de las sanciones sino porque nosotros nos las damos a nosotros mismos"[Habermas, 1991:31-32 y 42]. Veamos ahora cómo todo esto afecta el mundo institucional político y jurídico. 
3. La interrelación moral de lo político y lo jurídico en la reorientación de las instituciones

\begin{abstract}
La voluntad no está simplemente sujeta a la ley, sino sujeta de tal modo que debe ser observada como legislando para ella misma y sólo de este modo como siendo sujeta a la ley (de la cual ella se puede considerar autora). [Kant, Fundamentación de la Metafísica de las Costumbres, 434].
\end{abstract}

1. Como bien dice la cita de Moon usada al comenzar la parte II como epígrafe, Rawls no trata tanto de llegar al punto de vista moral sino que, suponiéndolo, elabora a partir de él una teoría de la justicia que ha de regir el orden institucional, incluido el jurídico, al menos en ciertas sociedades democráticas occidentales. Esta teoría está básicamente resumida en un principio, llamado por Rawls Principio general de justicia y que reza de la siguiente manera: "Todos los bienes sociales primarios -libertad, igualdad de oportunidades, renta, riqueza y las bases del respeto mutuo-, han de ser distribuidos de un modo igual, a menos que una distribución desigual de uno o de todos estos bienes redunde en beneficio de los menos aventajados". Este principio se expresa mejor en dos principios de justicia que son los siguientes:

Primer Principio: cada persona ha de tener un derecho igual al más extenso sistema total de libertades básicas compatible con un sistema similar de la libertad para todos.

Segundo Principio: las desigualdades económicas y sociales han de ser estructuradas de manera que sean para:

a- mayor beneficio de los menos aventajados, de acuerdo con un principio de ahorro justo, y

b- unidos a los cargos y las funciones asequibles a todos, en condiciones de justa igualdad de oportunidades.

La primera parte del segundo principio es conocida como principio de diferencia y está destinada a maximizar las posibilidades de los peor ubicados sin romper las garantías constitucionales prescriptas por el primer principio de justicia. A pesar de su preocupación, esta teoría de la justicia no aboga por una igualdad forzosa que destruya la libertad. Por ello es que los dos principios están gobernados por un orden lexicográfico, es decir, un orden que establece la jerarquía entre los principios de justicia para efectos de aplicación. Según este orden, el primer principio debe ser satisfecho antes del segundo y la primera parte del segundo principio antes de la segunda. Rawls define para esto dos normas de prioridad:

1- La prioridad de la libertad

Las libertades básicas sólo pueden ser restringidas en favor de la libertad. De tal forma: a) una libertad menos extensa debe reforzar el sistema total de libertades compartidas por todos. b) una libertad menor que la libertad igual debe ser aceptable para los que tienen una libertad menor.

2- La prioridad de la justicia sobre la eficiencia y el bienestar

La justicia prima sobre el principio de eficiencia y el de maximizar las ventajas y la igualdad de oportunidades prima sobre el principio de diferencia. De tal forma: a) la 
desigualdad de oportunidades debe aumentar las oportunidades de aquellos que tengan menos. b) una cantidad excesiva de ahorro debe, de acuerdo con un examen previo, mitigar el peso de aquellos que soportan esta carga.

Sobre estos principios, sus implicaciones sociales y económicas y su relación con el ordenamiento político abundan las presentaciones y discusiones en la literatura filosófica contemporánea. Me he referido a ellos ampliamente en Rawls, una herméutica pragmática, (Editorial Univalle, 1997). Aquí sólo me interesa señalar que esta teoría de la justicia, conformada por estos dos principios y por su orden lexicográfico, es lo que se conoce con el nombre de justicia como equidad (justice as fairness). A ella Rawls aspira a someter el ordenamiento jurídico e institucional de una sociedad que aspire a hacer de la justicia la primera virtud de las instituciones políticas.

En sus recientes textos, Rawls ha asumido que su teoría de la justicia no sólo podría resolver los conflictos entre diferentes doctrinas, ideologías y cosmovisiones porque es superior a ellas en sentido moral, sino que además tiene la capacidad de recibir el apoyo de las mismas gracias a su carácter eminentemente político. En otras palabras, que la 'justicia como equidad' es una concepción política de la justicia: en buena parte, esta condición estaría satisfecha por el hecho de que ella reduce su campo de aplicación a la estructura básica de la sociedad, no se nutre de aspectos doctrinarios acerca de la vida buena y rompe con toda pretensión metafísica. Gracias a eso, ella puede ser el objeto de un consenso traslapado de doctrinas comprehensivas razonables, consenso que es necesario para la unidad social en sociedades pluralistas. Este consenso, que es independiente de todos los contenidos comprehensivos de las diferentes doctrinas, se forma por la sumatoria de sus contenidos razonables y es por lo tanto un consenso moral, no únicamente un pacto de armisticio. Me he referido ampliamente a estas pretensiones en mi ensayo "Lo político en El liberalismo político de John Rawls" (Universidad Central de Venezuela, en prensa) y en "La justicia como equidad como una teoría kantiana" (Humanidades, IUS, 2000) y no es del caso ahondar en ellas aquí.

2. Desde su temprano texto La transformación estructual de la esfera pública hasta su reciente Facticidad y validez, Habermas ha insistido en una conexión entre la modernidad y la racionalidad expresada en la esfera pública, una conexión que, de un modo o de otro, provee las condiciones para un orden político moralmente justificado. En esto, Habermas se distancia de Horkheimer, de Adorno, de la tradición marxista y de los nietzscheanos críticos de la razón moderna. No es que Habermas no reconozca el papel que esa esfera ha cumplido en la dominación ideológica del capitalismo reciente. Es más bien que Habermas ve ese papel como el fruto de una tergiversación del proyecto original de la esfera pública burguesa, una transformación que terminó por imponer la racionalidad instrumental allí donde debería reinar la racionalidad moral. En su parecer, quienes condenan a la racionalidad moderna distinguen entre el proyecto inicial y su posterior transformación y adjudican a aquel lo que es criticable en ésta. El proyecto original de la esfera pública que la Modernidad introdujo tenía por función monitorear y legitimar el poder a través de las discusiones públicas. La posterior transformación por parte de un proceso de instrumentalización, en que tuvieron participación los medios de control sistemático del poder, ha alterado las relaciones debidas entre el Estado y la sociedad, de acuerdo con el proyecto inicial. Como consecuencia de esto, se ha dado una 'estatificación' de la 
sociedad (que se ha hecho a través de una regulación legal de diferentes niveles de la vida privada y de las relaciones humanas) y una 'socialización' del Estado (que se ha hecho a través de una canalización hacia el Estado de los intereses sociales sin ninguna discusión previa en la esfera pública); procesos ambos que han llevado a la destrucción de la separación entre las dos esferas. En lugar de la esfera pública, hay un área donde compiten descarnadamente diferentes grupos de intereses y donde la publicidad es usada para ganar aprobación y prestigio.

Pero la democracia guarda en sí potencialidades para revertir este imperio de la racionalidad instrumental y para ayudar a restituir, guiada por una filosofia práctica capaz de ofrecer una normatividad clara, una esfera pública que sea la concrección del viejo ideal de una sociedad que controle el poder político y le dé fundamento moral. Para ello acude a una sociología reconstructiva de la democracia que trata de identificar los "fragmentos de una razón que se ha incorporado en las prácticas políticas, aunque sean práticas distorsionadas" [Habermas, 1992: 285]. Ese es el papel de la teorización de la razón emprendido en su monumental obra La teoría de la acción comunicativa, especialmente a través del concepto de mundo de la vida tomado de Husserl y completado con la noción de competencia argumentativa de la filosofia aglosajona del lenguaje y de la psicología del desarrollo, como se presenta en Piaget y Koelberg. Con ello Habermas piensa una esfera pública como un "sitio transcendental donde se encuentran el emisor y el receptor, donde ellos pueden pretender que sus respectivas demandas y opiniones se ajustan a los mundos objetivo, social o subjetivo y donde ellas pueden criticar y confirmar la validez de esas pretensiones, ubicar sus desacuerdos y llegar a acuerdos" [Habermas, 1981, vol. II:126].

A manera de conclusión, es todavía mucho lo que falta por evaluar de estos proyectos filosóficos de restauración de la filosofía práctica alrededor de un concepto moral como el de justicia. Uno de los aspectos vitales para tal evaluación es su viabilidad. En otro ensayo ("¿Cómo responder a las demandas de los grupos monotemáticos? La preeminencia de lo moral sobre lo político y lo jurídico en Rawls y Habermas", conferencias de filosofía del derecho, Cátedra Gerardo Molina, Universidad Libre, 2001), he intentado extraer la posible posición de ambos pensadores frente a las demandas de justicia de las identidades colectivas y las respuestas constitucionales que va dando la Corte Constitucional colombiana. Un más completo balance de estos aspectos debe incluir el concepto de razón pública, que va tomando preeminencia en el pensamiento rawlsiano y que me parece implica una especie de 'constitucionalismo fijista', por oposición a cierta renovación democrática del derecho propuesta por Rawls. No hay todavía, que yo sepa, una evaluación adecuada del reciente ensayo de Rawls "La razón pública revisitada" (1997). En cuanto a Habermas, es mucho aún lo que falta no sólo por evaluar sino por entender. En lo que he dicho, apenas sí he tomado en cuenta Facticidad y validez, obra monumental y compleja cuyas implicaciones y pertinencias (o no) sobre el campo jurídico es un tema abordado intensamente en Alemania y, recientemente, en España. Entre nosotros, donde los estudios dirigidos por el profesor Guillermo Hoyos es el precedente más reconocido, no es mucho lo que hay escrito sobre esta obra, excepción hecha del ensayo del filósofo español Juan Antonio García Amado, publicado en la 'serie de teoría jurídica y filosofia del derecho' de la Universidad Externado de Colombia (No. 5, 1997). Las cosas, sin embargo, apuntan a cambiar. En el Grupo Praxis, Universidad del Valle, estamos emprendiendo un análisis de los recientes textos y sin duda similares esfuerzos 
se están emprendiendo en otras universidades colombianas. Es finalmente significativo el que estos temas estén interesando a las facultades de derecho (Universidad Libre, Icesi, Externado) lo que propiciará, sin duda, un diálogo interdisciplinar al respecto. Si este ensayo contribuye a ese diálogo y es críticamente superado por él, mi objetivo principal se habrá cumplido.

\section{Bibliografía}

A.J. AYER, Critique of Ethics and Theology (publicado en 1952 en Language, Truth, and Logic) en Essays on Moral Realisms, Cornell University Press, 1988.

Theodor ADORNO y Max HORKHEIMER, Dialectic of Enlightenment, 1944, traducción John Cumming, Continuum, 1996

Norberto BOBBIO , "El carácter del Iusnaturalismo" (1979), en Sociedad y Estado en la Filosofía Moderna, Norberto Bobbio y Michelangelo Bovero, Fondo de Cultura Económica, México, 1986.

,"El Poder y el Derecho" (1984), en Origen y Fundamentos del Poder Político, Norberto Bobbio y Michelangelo Bovero, Enlace-Grijalbo, 1986.

José FERNANDEZ SANTILLÁN, "Prólogo" en Origen y Fundamentos del Poder Político, Norberto Bobbio y Michelangelo Bovero, Enlace- Grijalbo, México, 1985.

Jurgen HABERMAS, Teoría de la Acción Comunicativa, (en alemán en 1981)Tecnos, Madrid, 1987, Theory of Communicative Action, Vol. I y II. Beacon Press, translated by Thomas McCarthy,1996.

,Moral Consciousness and Communicative Action,(en alemán 1983) The MIT Press, Cambridge, 1990. Justification and Application: Remarks on Discourse Theory, (en alemán 1991) The MIT Press, 1993.

,The Philosophical Discourse of Modernity, Twelve Lectures, The MIT Press, Cambridge, 1987.

,Facticidad y Validez (en alemán 1992) Editorial Trotta, 1998. (Between Facts and Norms, Cambridge, The MIT Press, 1996)

,Reconciliación Mediante el Uso Público de la Razón, en Jurgen Habermas/ John Rawls: Debate sobre el Liberalismo Politico, Paidós I.C.E./U.A.B. 1998

, Struggles for Recognition in the Democratic Constitutional State, en Multiculturalism, editado por Amy Gutman, Princeton Universirty Press, 1994.

,On the Problem of Understanding Meaning in the Empirical-Analytic Sciences of Action, en On the Logic of the Social Sciences, The MIT Press, 1996.

,The Hermeneutic Claim to Universality, en Contemporary Hermeneutics. Hermeneutics as Method, Philosophy and Critique por Josef Bleicher, Routledge, London, 1990

,Hermeneutics and the Social Sciences, en The Hermeneutics Reader, editado por Kurt Mueller-Vollmer, Continuum, New York, 1994

Agnes HELLER What is and what is not practical reason, en Universalism vs. Communitarianism, editado por David Rasmussen, The MIT Press, 1990

Guillermo HOYOS, Democracia y Derecho. El Debate entre Habermas y Rawls, 1998.

Immanuel KANT, Fundamentación de una Metafísica de las Costumbres, Espasa Calpe, Madrid, 1983 (Grounding for the Metaphysics of Morals, translated by James Ellington, Hackett Publishing co. 1981). 
,Crítica de la Razón Práctica, Editorial Porrúa, México, 1986 (Critique of Practical Reason, Prometheus Books, 1996).

Karl MARX, El Dieciocho Brumario de Luis Bonaparte, en C.Marx F.Engels Obras Escogidas, Editorial Progreso, Tomo I, Moscú, 1976.

Thomas McCARTHY Kantian Constructivism and Reconstructivism: Rawls and Habermas in Dialogue, in Ethics,105,Oct.1994 